\title{
Direction et gestion administrative du caloines
}
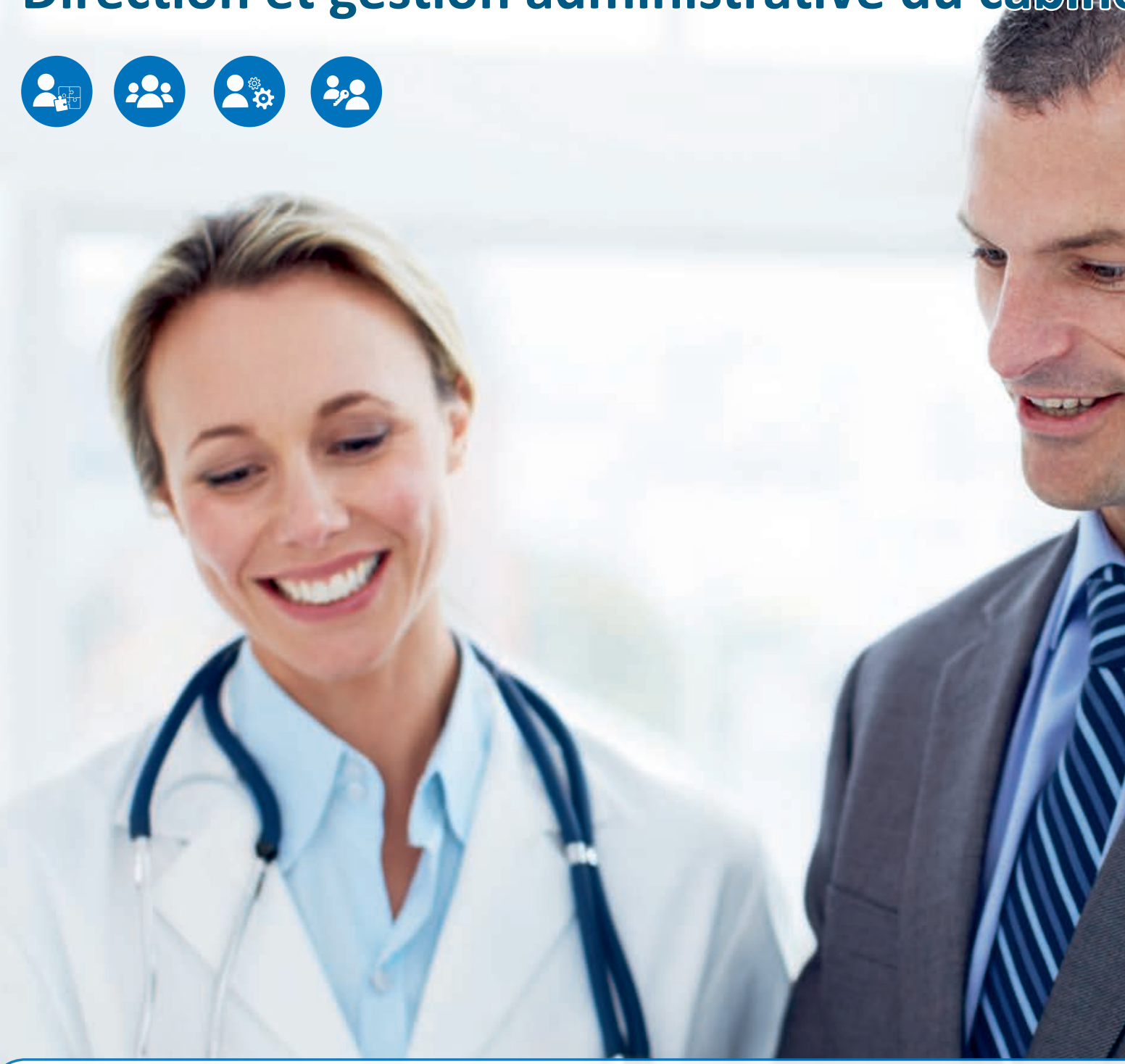

Les médecins indépendants sont exposés à une charge administrative croissante dans leur quotidien. FMH Services vous libère volontiers de ces tâches et vous apporte son soutien dans différents domaines:

- Direction, gestion administrative du cabinet, gestion et conduite du personnel, optimisation des processus, conseil juridique

- Comptabilité, administration des salaires, planification financière, controlling, facturation

- Conseil en matière d'assurances et gestion des assurances

\section{DIRECTION ET GESTION ADMINISTRATIVE DU CABINET}

\section{\FMHSERVICES}

Vous pouvez prendre contact avec nous sans aucune obligation par téléphone ou courrier électronique ou en nous retournant le talon-réponse par fax ou par la Poste. Nous vous contacterons.

Prénom / nom

Adresse

NPA / lieu

Téléphone privé / prof.

Atteignable de préférence vers

\section{CONSULTING}

\section{FMH Consulting Services AG}

Avenue d'Ouchy 66, 1006 Lausanne

Tél. 0219224435

mail@fmhconsulting.ch - www.fmhservices.ch 